\title{
A Bilevel Programming Location Approach to Regional Waste Electric and Electronic Equipment Collection Centers: A Study in China
}

\author{
Honglei Li iD and Yi Lu \\ School of Management, Liaoning Normal University, Dalian 116029, China \\ Correspondence should be addressed to Honglei Li; lhl@lnnu.edu.cn
}

Received 14 November 2020; Revised 13 January 2021; Accepted 13 January 2021; Published 25 January 2021

Academic Editor: Shib S. Sana

Copyright (C) 2021 Honglei Li and Yi Lu. This is an open access article distributed under the Creative Commons Attribution License, which permits unrestricted use, distribution, and reproduction in any medium, provided the original work is properly cited.

\begin{abstract}
As one of the largest markets of electronic and electric equipment, China has not completely established the formal recycling system of WEEE compared with the developed countries. As a result, China is facing the huge challenge of resource waste and water/soil environmental pollution. In this paper, according to the current regulations on WEEE recycling and disposal issued by Chinese government, the business model of the Chinese WEEE recycling system was designed, and a bilevel programming-based model was proposed to help the disposal factories to establish the regional efficient and economical WEEE recycling network. This model addressed the optimization of bilateral benefits of disposal factories and the third-party recycling agencies/stations. An experiment based on a regional WEEE recycling business data was solved by the NSGA algorithm to validate the proposed model. With the result, the proposed model was compared with the related studies on Chinese WEEE recycling network planning. With the comparison and the analysis on the experiment result, it was found that the proposed model had considerably stable convergence and optimization performance, which proved that this model can be regarded as a useful tool to the planning of the Chinese regional WEEE recycling network. In the last part, the future improvement of the proposed model was also discussed.
\end{abstract}

\section{Introduction}

The demand for electric and electronic equipment is growing very rapidly. Moreover, the life cycles of these products get shorter. It results in a growing amount of waste electric and electronic equipment (WEEE) which needs to be reused or disposed for the economic and environmental purpose. In WEEE, there are much precious renewable materials. For example, there are 35 percent of components made of metal in computers and the proportion of $\mathrm{Cu}$ is about 20 percent (Luo et al., 2006) [1]. In addition, the top 1 component, plastic, can be used as a kind of fuel, which produces the energy 1.3 times of that of coal. The treatment of WEEE not only protects the environment but also makes commercial benefits. Therefore, the disadvantage of maltreatment and the advantage of right treatment have drawn great attention from the public.

Many countries, especially the developed ones, have promulgated acts to recycle WEEE. The USA issued the compulsory act on WEEE treatment in the early 1990s and more acts on the recycle of WEEE in 2002 (Lu et al., 2014) [2]. In the USA, most states enforce the producer responsibility with which the producers are responsible for the recycle of WEEE and pay for the recycle cost. The customer responsibility which forces the customers to pay for the recycle is also enforced in other states. At present, more than 96 percent of the WEEE is reused while the rest is disposed as rubbish (Yang et al., 2019) [3]. The European Union passed WEEE (2002/96/EC) and RoHS (2002/95/EC) to guide member countries to regulate the recycle of WEEE. The two directives state that the producers pay the cost of the recycle and disposal of WEEE and the nonprofit organizations dispose of the WEEE (Robinson, 2009) [4]. In Japan, producers are responsible for the disposal of WEEE and the dealers recycle and deliver the WEEE to producers. Different from other countries, Japanese customers are obligated to pay the cost of recycle according to the kind of WEEE and it 
is illegal to abandon WEEE anywhere (Menikpura et al., 2014; Xu and Zhou, 2019) [5, 6].

Many developing countries also start making an effort on building infrastructures for WEEE reverse logistic network design processes (Temur and Bolat, 2017) [7]. According to the report of Chinese electronic and electrical equipment (EEE) market in 2019, the overall turnover of EEE in Chinese market reached 126 billion dollars in 2019 (CCID, 2020) [8]. The People's Daily reported that according to the white paper on the recycling, processing, and comprehensive utilization of China's WEEE released by the China household electrical appliance research institute (CHEARI), in 2018, about 150 million TV sets, refrigerators, air conditioners, washing machines, and computers were scrapped. The weight of the WEEE theoretically exceeded 4.06 million tons. It is optimistically estimated that amount all WEEE, only 50 to 60 percent of all has been formally disposed of (Kou, 2020) [9]. As the largest developing country, China is facing the huge challenge of WEEE treatment.

Contrary to the developed countries, China has not completely established the regular recycle system of WEEE. The Chinese recycling business model (Figure 1) showed that in China, the WEEE was mainly collected by recycle individual agencies/stations rather than dealers and producers, and the customers sold WEEE to individual recycling agencies/stations and then the agencies sold WEEE to WEEE disposal factories. It is a kind of commercial business. Since the customers are not compulsory to hand in WEEE in right way, some WEEE is even abandoned as rubbish, which may cause the serious environmental pollution. According to the investigation, nearly 90 percent of WEEE is not processed in a formal way in China (Intelligence Research Group, 2019) [10].

According to official reports, there are about 90,000 registered recycling agencies/stations and more than 300,000 unregistered ones in China. More than 90 percent of the WEEE is transferred to disposal factories by these recycling agencies/stations. The recycling agencies/stations play the important role in the recycling system. For examples, there are more than 5000 ones in Beijing, which is only an ordinary epitome of the distribution of the Chinese recycling network. In general, these recycling agencies/stations are in small size and equipped with poor facilities. They are generally scattered in city districts, self-owned, or run by unemployed persons. They collect all kinds of renewable materials including WEEE manually and sort out the materials to transfer them to different disposal factories.

In order to improve the normal disposal of WEEE, Chinese government has been enforcing the regulations and licensing on the WEEE recycling and disposal industry from 2011. Unlicensed organizations are banned to recycle and dispose of WEEE. With these measures, Chinese WEEE business has been developed to some extent in nearly 10 years. Until 2018, there were 109 disposal companies added into the licensed list. In order to support the sustainable running of disposal companies, Chinese government also enacted WEEE disposal fund regulation (WDFR) to establish the disposal fund to provide subsidies to disposal factories from 2012. According to the regulation, the EEE producers and importers pay for the fund according to the product category and production volume (The
State Council of People's Republic of China, 2012) [11]. However, there still exist many problems faced by all disposal factories (Ministry of Commerce of People's Republic of China, 2018). (a) Low income: the main income of Chinese WEEE disposal companies is derived from the sales of decomposed components from WEEE and the financial support by the government. According to the investigation by the Intelligence Research Group, by the end of 2018, the recycling fund had collected 2.36 billion dollars and allocated 2.28 billion dollars in subsidies, which barely maintained a balance [12]. (b) High recycling cost: in China, since the recycle logistics chain is much longer and composed of individual recycling agencies with diverse scale and capability, the efficiency of the recycle logistics systems is considerably poor. In addition, the money paid to the citizens to collect the WEEE further increased the cost of recycling. That meant the total cost was eventually afforded by the disposal factories. With the low operation efficiency and the high cost of the recycling, the WEEE disposal factories made too little profit to survive. It was reported that even with the financial support which was about 60 percent of the disposal factories' total income, nearly 66 percent of them were about to pause running or go bankrupt (Intelligence Research Group, 2019) [10].

From 2014, Chinese government upgraded the subsidies' requirements. The disposal companies cannot get the subsidies from the government any more if the amount of the disposal of WEEE is lower than 20 percent of the licensed disposal capacity. This measure helped regulate the WEEE disposal industry. Qualified companies would get more support to maintain the sustainable business while those who failed to meet the requirements would be excluded from the market. However, WEEE is still recycled from the public with money and directly transferred to the disposal plants by the recycling agencies/ stations. In addition, the producers and retailers are still not enforced but only encouraged to collect WEEE as possible as they can. In fact, few of them are willing to participate in the recycling business considering the extra workload.

As was described above, in the special business model in China, the WEEE disposal factories had to establish their own collection centers to pack all small batches of WEEE from recycling agencies/stations into big batches in order to decrease the collection cost. Meanwhile, they also take the benefits of the recycling agencies/stations into account to collect more WEEE.

In this paper, the bilevel programming approach was used to assist disposal factories to establish an efficient and economical recycling network. The work addressed the special WEEE business situation in China. On the one hand, by satisfying the benefit interest of the public in WEEE recycling, disposal factories will collect as much WEEE as possible to meet the basic conditions for obtaining government subsidies. On the other hand, the approach will help factories to decrease the cost of recycling logistics so as to make more profit to survive.

\section{Related Study}

Many related studies on WEEE recycling network planning have been launched recent years. Optimization and simulation are the prevailing methods used in the related studies. 


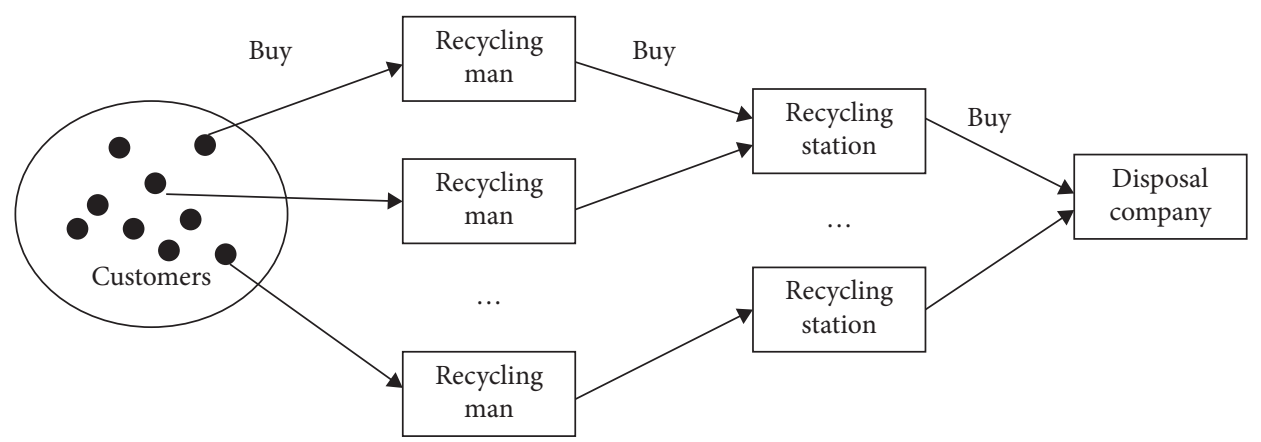

Figure 1: The WEEE recycling business process in China.

2.1. Simulation-Based Study. Golinska and Kawa (2012) proposed a model based on graph theory and agent technology that provided dynamic configuration of the recovery network among a pool of cooperating companies in dynamically changing conditions [13]. Shokohyar and Mansour (2013) developed a simulation optimization model to determine the best locations for the collection centers and also recycling plants for WEEE. In their work, economic, environmental, and social issues were considered to help the government to simultaneously perform the trade-off between environmental issues and economical and social impacts. The proposed model was examined through an illustrative case study from a developing country's WEEE situation [14]. Ravi et al. (2017) measured the performance of the reverse logistic enterprise with the agent-based simulation model. They designed all kinds of agents in the reverse logistic business: collector agent, sorting-cum-reuse agent, remanufacturing agent, recycler agent, supplier agent, and distributor agent. The model implemented the whole recycling process from collection to disposal to simulate the activities in a cost-effective manner. Eventually, the recommendations were given to improve the total performance of the reverse logistic enterprise [15]. Popa and Cotet (2017) proposed a material flow management optimizing algorithm based on a virtual model of the selecting and processing architecture of the waste collection integrated system. The material flow management of this system was based on its virtual model in order to identify and eliminate material flow concentrators and increase productivity. Simulation was used to diagnose the initial performance of the system structural elements as well as to validate the optimized system performances after eliminating the bottlenecks [16]. Llamas et al. (2020) designed a very large simulation model linking up to 223 detailed modeled unit operations, over 860 flows and 30 elements, and all associated compounds to analyze the resource efficiency limits and evaluate the material recovery, resource consumption, and environmental impacts of different processing routes of the circular economy system [17]. Suyabatmaza et al. (2014) considered manufacturers that strategically decided to outsource the company specific reverse logistics activities to a third-party logistics (3PL) service provider. They proposed a hybrid simulation-analytical modeling approach which iteratively used mixed integer programming models and simulation to create the framework for handling the uncertainties in the stochastic reverse logistics network design problem [18].
2.2. Optimization-Based Study. Mar-Ortiz et al. (2011) studied the optimization of the design of the reverse logistic network for the collection of WEEE in the Spanish region of Galicia. They proposed a three-phase hierarchical approach. The first phase is for the facility location by means of a mixed integer linear programming, and the second phase is for the corresponding heterogeneous fleet vehicle routing with a new integer programming formulation and a savings-based heuristic algorithm. The third phase is a simulation study on the collection routes in order to assess the overall performance of the recovery system. They claimed that the performance of the proposed procedure was good and the configuration of the recovery network was improved, compared to the one currently in use whose transportation costs were reduced by nearly 30 percent [19]. Tari and Alumur (2014) studied the collection center location problem with equity considerations within reverse logistics network design. The aim of the problem is for three objectives. The first one is to minimize total cost, the second one is to ensure equity among different firms, and the third one is to provide steady flow of products to each firm. The multiobjective mixed integer programming formulation was used considering the changes in the fixed costs and container capacities, changes in the amount of supply, and changes in the growth rate. An implementation of the problem in Turkey within the context of WEEE collection was presented to illustrate the potential of the model and value of using a multiperiod model as opposed to using a static one [20]. Baxter and $\mathrm{B} \emptyset$ (2017) launched a detailed analysis of the logistical and cost-effectiveness of the collection and transport of WEEE in Norway. The study revealed regional geography to be a particularly important factor which varied significantly across the country and heavily influences the cost of collection. The study also explored the influence of other factors relating to operational effectiveness and customer service in the WEEE collection and transport business [21]. Di et al. (2013) proposed a bilevel programming model to collection station location choice. The top level aimed at the minimum total cost and the maximum volume of the WEEE collection. The bottom level aimed at the maximum satisfaction of the customers considering the collection price paid to customers and the distance between collections and customers. The model was proved to be beneficial to determine the number of establishing collection stations, location, and the served customers and more beneficial to the 
waste household appliance recycling management [22]. Huang and Zhang (2018) constructed the improved maximum coverage location model of waster mobile phone recycling business points and used Lagrangian relaxation algorithm with subgradient optimization to solve the model. It was proved that the model and the designed algorithm which had good practicality can guide the government or companies to deal with the waste mobile phone recycling problem [23]. Yu and Solvang (2016) suggested a general reverse logistics network and formulated it through multiobjective mixed integer programming. The reverse logistics system was an independent network and comprised of three echelons for collection, recycling, and disposal of waste. Their work explicitly showed the trade-off between the costeffectiveness for improving environmental performance, and influences from resource utilization had great practical implication on decision-making of network configurations and transportation planning of a reverse logistics system [24].

The above related studies have proved that simulation methods and optimization methods contribute most to the WEEE recycling business in practical and academic domains. However, the models in the related studies did not exactly and completely address the current situation of WEEE recycling business in China. In most models, the cost for the collection of WEEE from the customers (WEEE holders) was not taken into account and the recycling stations were assumed established by disposal companies. The bilevel programming model of Di et al. (2013) considered the collection cost of WEEE and took it as an important factor in the model. However, their study aimed at establishing the recycling stations especially for WEEE, which was not feasible because most recycling stations, and recycling vendors worked for all kinds of renewable resources and their business is independent of disposal factories.

\section{Problem Definition}

According to the Chinese WEEE recycling business model in Section 1, it was hypothesized as follows:

(1) Since the third-party recycling agencies/station network had been established, the location, capacity, and number of recycling agencies/stations were predetermined.

(2) Since the concerns about the environment pollution, the number and the location of disposal factories was usually predetermined and authorized by the local government before the planning of collection centers. Therefore, in this business model, there was only one disposal factory in a certain area, whose location and disposal capacity was predetermined.

(3) All WEEE must be transferred from recycling agencies/stations to collection centers established by disposal factory, and the links between recycling agencies/stations and collection centers were fixed.

(4) The collection price of WEEE was determined in WEEE categories by the disposal factory.
(5) Since most recycling agencies/stations were owned by individuals, the recycling price paid to the customers by different recycling agencies/stations varied to some extent.

(6) The time windows of collection centers were deployed with different values by the disposal factory in order to schedule the WEEE delivery tasks of collection centers in good order without confusion.

Considering the nature of the location problem, the bilevel programming algorithm was used to design the location models (Figure 2). The top-level model addressed the concern of the disposal companies about the collection volume and cost. The bottom-level model addressed the benefits of the third-party recycling agencies/stations.

3.1. The Multiobjective Optimal Model in Top Level. In top level, the disposal factories aimed at the maximum collection volume and the minimum collection cost. The collection volume was the total collection volume of all collection centers. The collection cost included construction cost, regular operational cost, and the transportation cost of all collection centers. The optimal model in top level was defined in the following equations. It was a typical multiobjective programming problem. In equation (1), the total cost of the WEEE recycling network was defined as the minimum sum of construction cost of collection centers $\left(k A_{j}\right)$, the operational cost of collection centers $\left(t_{j} O_{j}\right)$, and the transportation cost of collection centers $\left(V_{j} R_{j} d_{j}\right)$, while in equation (2), the maximum total WEEE collection volume from collection centers was defined. The two objectives were in opposite optimal directions, which hinted that they can hardly be integrated into one single objective:

$$
\begin{aligned}
\min T_{c} & =\sum_{j=1}^{N} y_{j}\left(k A_{j}+t_{j} O_{j}+V c_{j} R_{j} d_{j}\right), \\
\max V_{c} & =\sum_{j=1}^{N} y_{j} V c_{j},
\end{aligned}
$$

s.t.

$$
\left\{\begin{array}{l}
\sum_{j=1}^{N} y_{j} k A_{j} \leq T_{I} \\
\sum_{j=1}^{N} y_{j}>0, \\
V c_{j} \leq \overline{V c_{j}}, \\
0.2 V_{T} \leq \sum_{j=1}^{N} y_{j} V c_{j} \leq V_{T}, \\
y_{j} \in\{0,1\}, j=1, \cdots N,
\end{array}\right.
$$

where $t_{j}$ was the time window of collection center $j$. In this model, the time window was a kind of relative value, where

$$
t_{j}=\frac{\text { work hours }}{8} \text {. }
$$

$T_{I}$ was the budget of total construction cost of collection centers and $A_{j}$ was the construction area size of collection 


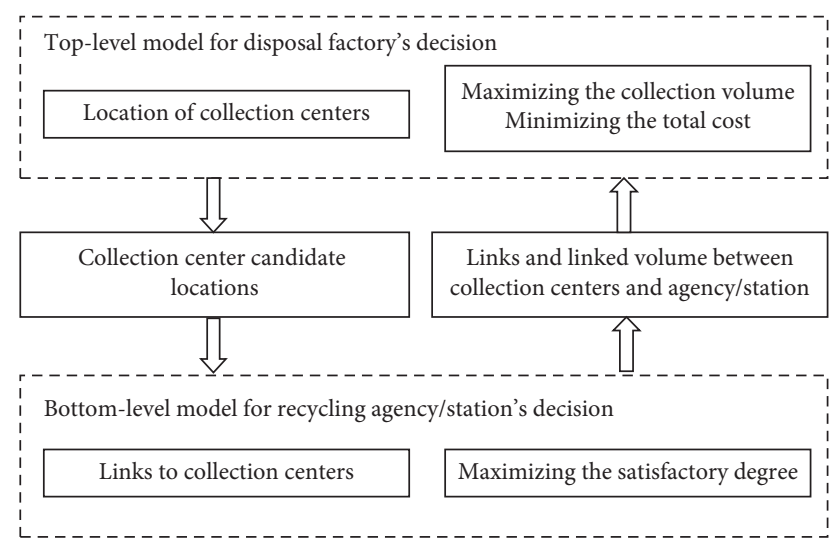

FIGURE 2: Bilevel programming model for location of WEEE collection centers.

center $j$. K was the construction cost per $\mathrm{m}^{2}$. As was defined in equation (3), the construction cost of all collection centers cannot exceed the budget $T_{I}$. $O_{j}$ was the unit operational cost, and $y_{j}$ was the variable to decide whether to set up the collection center $j\left(y_{j}=1\right)$ or not $\left(y_{j}=0\right)$ (as defined in equation (3)). As was defined in equation (3), there was at least 1 collection center set up in the planning area. $\mathrm{Vc}_{\mathrm{j}}$ was stock volume of collection center $j$, and $\overline{V c_{j}}$ was the max stock volume of collection $j$. As was defined in equation (3), $V c_{j}$ should be less than $\overline{V c_{j}}$. $V_{T}$ was the annual licensed disposal capacity divided by the average times of the transportation from collection centers to disposal factory. The average times were estimated by the disposal factories according to their recycling business experience. Equation (3) meant that the disposal factories cannot work if they did not live up to the requirement of getting the fund from the government. $R_{j}$ was the unit transportation cost from collection center $j$ to disposal factory, and $d_{j}$ was the distance between collection center $j$ and disposal factory. $N$ was the maximum number of candidate collection centers.

3.2. The Optimal Model in Bottom Level. In bottom level, the third-party recycling agencies/stations ran for higher income with lower WEEE recycling cost. The transportation distance to the collection centers, the recycling price, and the time window of collection centers were key factors to influence their business. The optimal model in bottom level was defined in the following equations:

$$
\max U=\sum_{i=1}^{M}\left(p_{x_{i}}-p_{i}-R_{i x_{i}} d_{i x_{i}}\right) V r_{i}^{\prime} t_{x_{i}}
$$

s.t.

$$
\begin{gathered}
\sum V r_{i}^{\prime} \leq V c_{x_{i}}, \quad i=1, \cdots M, j=1, \cdots N, \\
V r_{i}^{\prime} \leq V r_{i}, \quad i=1, \cdots M,
\end{gathered}
$$

where $x_{\mathrm{i}}$ was the variable to decide whether recycling agency/station $i$ delivered WEEE to collection center $j$ $\left(x_{\mathrm{i}}=j\right), p_{i}$ was the price recycling agency/station $i$ paid to the customers when collecting WEEE from customers, $p_{x_{i}}$ was the price paid by collection center $x_{i}$ to the recycling agency/ station $i, R_{i x_{i}}$ was the transportation fee rate from recycling agency/station $i$ to collection center $x_{i}, d_{i x_{i}}$ was the distance from recycling agency/station $i$ to collection center $x_{i}, V r_{i}$ was the maximum capacity of recycling agency/station $i, V r_{i}^{\prime}$ was the WEEE capacity of recycling agency/station $i$ transferred to collection center $x_{i}$, and $M$ was the number of recycling agencies/stations.

As was defined in equation (4), $\mathrm{U}$ was the utility function of recycling agencies/stations, which was taken as the weighted profit of all recycling agencies/stations. The weights were the time window of collection centers. The larger the time window was, the more convenient for recycling agencies/stations to transfer WEEE. In equation (5), the total volume of recycling agencies/stations cannot exceed the volume of the collection center that was linked with the recycling agencies/stations.

\section{Method to Solve the Problem}

4.1. Method to Solve the Bilevel Programming Location Model. Bilevel programming was proved to be a typical NP-hard problem. The models based on bilevel programming were usually solved by heuristic algorithms such as genetic algorithm (GA), ant colony algorithm (ACO), and simulated annealing (SA). In this study, GA was used to solve the bilevel-based location model of WEEE collection centers.

The GA family has many branches. Since the optimal model in top level was multiobjective-oriented with nonweighted objectives, the nondominated sorting genetic algorithm (NSGA) (Srinivas, N. and Deb, K., 1994) was considered to solve the optimal model. As one of the most well-known multiobjective optimal algorithms, NSGA has three versions, NSGA-I (1994), NSGA-II (2002), and NSGAIII $(2014)[25,26]$. The basic framework of NSGA-III remains similar to the original NSGA-II with significant changes in its selection mechanism. Unlike in NSGA-II, the maintenance of diversity among population members in NSGA-III is aided by supplying and adaptively updating a number of well-spread reference points (Deb, K. and Jain, H., 2014) [26]. As compared with NSGA-II and other multiobjective optimal algorithms, NSGA-III significantly reduces the computation cost, especially for high-dimension multiobjective problems. For low-dimension multiobjective problems such as the proposed model in this paper, NSGAII and NSGA-III are all suitable. However, considering NSGA-III is the latest improved version of NSGA-II, we chose it as the preferred algorithm.

According to the bilevel programming process in Section 3 , the NSGA-III algorithm was realized as shown in Figure 3. The feasible location schemes of collection centers were generated and passed to the GA algorithm in the bottom level to get the optimal business collaboration between collection centers and recycling agencies/stations. Then, the optimal location scheme of collection centers was got.

In the above NSGA algorithm, the encoding scheme of the feasible location scheme of collection centers was defined as the binary-like chromosome shown in 


$$
c c=\left\{y_{1}, y_{2}, \cdots y_{N}\right\},
$$

where $y_{j}=1$ meant a collection center was set up at position $j$ and $y_{j}=0$ meant a collection center was not set up at this position.

The optimal model in bottom level was single objectiveoriented, so the classical genetic algorithm was used to get the optimal solution in bottom level (see Figure 4). The algorithm performed genetic operations (selection, crossover, and mutation) and repeated the operations driven by the algorithm in Figure 2 until the optimal solution of the top-level model was got.

In this algorithm, the encoding scheme $r c$ and the feasible solution of business collaboration between recycling agencies/stations and collection centers was defined as the integer vector in

$$
r c=\left(x_{1}, x_{2}, \cdots x_{m}\right) .
$$

The value of $x_{i}$ was the collection center to which recycling agency/station $i$ transferred WEEE. For example, one feasible location solution of collection centers in the toplevel model was $c c=(0,0,1,0,0,0,1,0,0,0,0,1)$ (see equation (8)). In cc, $y_{3}=y_{7}=y_{12}=1$, it meant that only collection center 3,7 , and 12 were set up to collect WEEE from all recycling agencies/stations. Thus, one feasible solution in the bottom-level model can be defined as $r c=(3,3$, $7,3,12,12,7,3,12,7,12,7,3,12,12,7,7)$ (see equation (9)). In $r c, x_{1}=x_{2}=x_{4}=x_{8}=x_{13}=3$, it meant that recycling agency/station $1,2,4,8$, and 13 transferred WEEE to collection center 3 .

4.2. Validation of the Model. The validation dataset was about the business of a city in China. There were 44 third-party recycling agencies/stations and 18 candidate collection centers scattered in the city. The total investment $\left(T_{\mathrm{I}}\right)$ was up to 10 million yuan. The annual disposal licensed capacity was 1.5 million, and the average time of transportation from collection centers to disposal factory was 100 . Therefore, $V_{T}=15000$.

The raw data about recycling stations and candidate collection centers were collected by the authors in 2014. The distance between collection centers and disposal factory was measured by ArcGIS with longitude and latitude data, so was the distance between collection centers and recycling agencies/stations. The final dataset for validation is shown in Tables 1-3.

The parameters of NSGA and GA are shown in Table 4.

Geatpy (Jazzbin, 2020), an evolutionary algorithm toolbox and framework with high performance in Python [27], was used to implement the bilevel programming algorithms due to the following features:

(1) As open source software written in pure Python, Geatpy helps researchers easily implement complex models with templates in programming mode such as MatLab

(2) Be capable of solving single-objective, multiobjective, many-objective, and combinatorial optimization problems

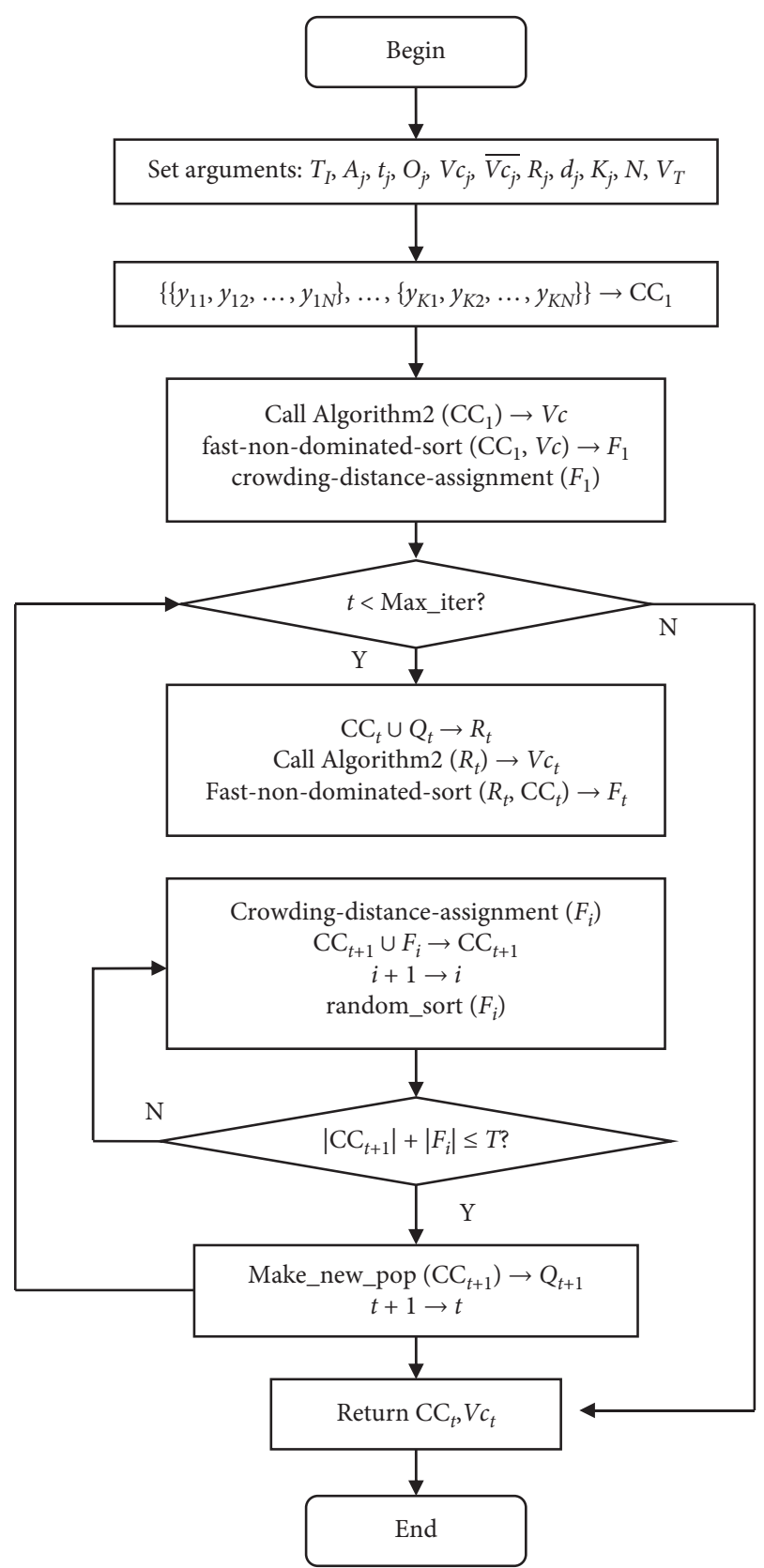

FIgURE 3: Algorithm to solve the top-level model.

(3) A huge number of operators with high performance of evolutionary algorithms (selection, recombination, mutation, and migration)

(4) Many evolutionary algorithm templates, including GA, DE, and ES for single-/multiobjective evolution

(5) Support parallelization and distribution of evaluations

(6) Support tracking analysis of the evolution iteration

The algorithms were repeatedly performed in 20 turns to validate the stability. The values of objective function $f 1$ and $f 2$ are shown in Table 5.

In this experiment, there was only one nondominated solution in each run, which demonstrated a seemingly 


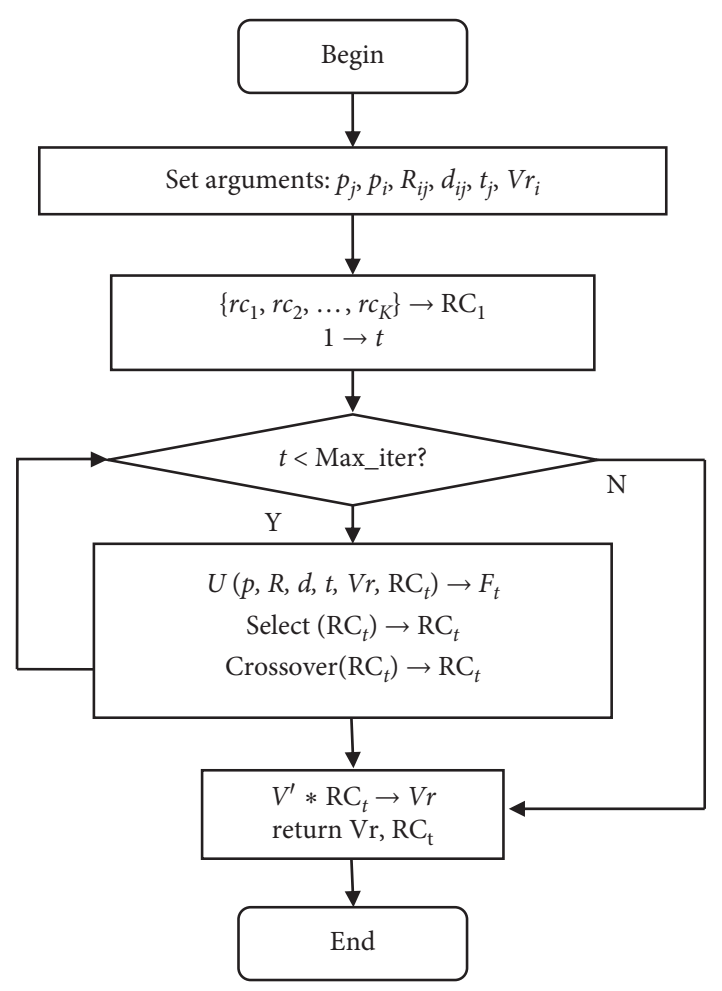

FIGURE 4: Algorithm to solve the bottom-level model.

confusing result. Through the tracking analysis of the evolution process, it was found that in the bottom-level model, all recycling agencies/stations tried to transfer WEEE to collection centers as more as possible (see equation (6)), which made $f 2$ (the total volume of collected WEEE) at a stably highest level in each run. The value of $f 2$ would be the total of the maximum capacity of all recycling agencies/ stations (if the total was less than $V_{T}$ ) or $V_{T}$ (if the total was larger than $V_{T}$ ). The result hinted that the third-party recycling agencies/stations had the overwhelming impacts on Chinese WEEE recycling business.

With the fixed value of $f 2, f 1$ would theoretically converge to a stable level. The convergence level of $f 1$ was analyzed in the hypothesis test. The normal distribution test was used to test the distribution of the sampling error of $\mathrm{f} 1$. The $p$ value was $0.278(\alpha=0.05)$, which meant that there was no significant difference in the values of $\mathrm{fl}$ in all runs.

One of the feasible solutions was selected as the final solution of the location problem. Figure 5 shows the evolution process of $f 1$. The optimal solution was got at iteration 78. The values of $f 1$ and $f 2$ were 5219652 and 4394. The collaboration between recycling agencies/stations and collection centers is shown in Table 6 .

\section{Discussion}

There were some representative related studies on Chinese WEEE recycling business. For example, Di et al. (2013) considered the collection cost of WEEE and took it as an important factor in the model. Their study aimed at establishing the recycling stations especially for WEEE, which was not feasible because most recycling agencies/ stations and recycling vendors worked for all kinds of renewable resources and their business was independent of disposal factories. Huang and Zhang (2018) constructed an improved maximum coverage location model of waste mobile phone recycling point, using the waste mobile phone recycling spatiotemporal demand retrieved by mobile signaling data mining, and the position and quantity of demand were all changing [23]. They considered the cluster feature of mobile users to plan the location of collection centers, and it was not suitable for all kinds of WEEE. Furthermore, the third-party recycling agencies/stations as the major WEEE recycling institutions were not considered in their model, and it was not factual in the Chinese WEEE recycling market. Di and Wang (2012) proposed a 2-objective optimal model to plan the Chinese WEEE recycling network. The definition of 2 objective functions was similar to that of the model in this paper. To solve the multiobjective model, the values of 2 objective functions were separately calculated and normalized, and then weighted sum method was used to transform the multiobjective model into a single-objective model [28]. However, there were some aspects that could be argued: (1) the possible conflicts of 2 objectives were taken as negative problems. In fact, in multiobjective problems, conflicts of objectives were common and acceptable. (2) The validity of the transformation method was uncertain because it was difficult to determine the reasonable values of the weights of objective functions.

Compared with the related studies, the proposed model addressed the location problem of the Chinese WEEE recycling network and adequately reflected the demand of disposal companies in the Chinese WEEE industry. The features of this study are summarized in the following aspects:

(1) Since the third-party recycling agencies/stations were independent of disposal factories and running with different capacity, the benefits of third-party recycling agencies/stations were also taken into account other than related studies.

(2) Compared with the multiobjective and single-objective algorithms used in related studies, the nondominated solution tactic was more reasonable and universal than those of other algorithms.

(3) In the implementation part of the proposed model, in order to simplify the algorithm, the encoding scheme of feasible solutions was also elaborately designed. It was noted that in the bottom-level model, the collaborations among recycling agencies/stations and collection centers were defined by a M-dimension vector (see equation (9)) other than by the traditional $\mathrm{M} * \mathrm{~N}$ matrix shown in equation (10). With the M-dimension vector, a feasible solution containing $M$ numbers was evaluated by GA, which significantly reduced the complexity of the bottom-level model and saved more computation time: 
TABLE 1: Information about candidate collection centers.

\begin{tabular}{|c|c|c|c|c|c|c|c|c|}
\hline ID & Distance & Collection price & Area & Volume & Trans. fee rate & Operation fee & Time window & K \\
\hline 1 & 14.1 & 17 & 1000 & 800 & 1.8 & 160 & 0.95 & 1000 \\
\hline 2 & 10.2 & 15 & 1000 & 700 & 1.7 & 180 & 1 & 1000 \\
\hline 3 & 15.6 & 16 & 850 & 700 & 1.75 & 180 & 1 & 900 \\
\hline$\cdots$ & $\ldots$ & $\cdots$ & $\ldots$ & $\cdots$ & $\ldots$ & $\cdots$ & $\cdots$ & $\cdots$ \\
\hline 15 & 9.2 & 15 & 850 & 800 & 1.7 & 180 & 0.9 & 1100 \\
\hline 16 & 14.1 & 16 & 1200 & 800 & 1.8 & 180 & 1 & 1000 \\
\hline 17 & 16 & 17 & 900 & 900 & 1.7 & 180 & 0.95 & 900 \\
\hline 18 & 13 & 15 & 1000 & 850 & 1.5 & 150 & 1.1 & 1000 \\
\hline
\end{tabular}

TABLE 2: Information about recycling agencies/stations.

\begin{tabular}{lcc}
\hline ID & Volume & Collection price \\
\hline 1 & 80 & 12 \\
2 & 120 & 13 \\
3 & 80 & 13 \\
$\ldots$ & $\ldots$ & $\ldots$ \\
42 & 72 & 13 \\
43 & 89 & 13 \\
44 & 60 & 12 \\
\hline
\end{tabular}

TABLE 3: Information about transportation between collection centers and recycling agencies/stations.

\begin{tabular}{lccc}
\hline Collection centers & Recycling agencies/stations & Distance & Trans. fee rate \\
\hline 1 & 1 & 2 & 1.8 \\
1 & 2 & 5 & 1.7 \\
1 & 3 & $\ldots$ & 1.75 \\
$\ldots$ & $\ldots$ & 4.5 & $\ldots$ \\
2 & 1 & 6.4 & 1.6 \\
2 & 2 & 3 & 1.7 \\
2 & 3 & $\ldots$ & $\ldots$ \\
18 & $\ldots$ & 2.2 & 1.7 \\
\hline
\end{tabular}

TABLe 4: Parameters of NSGA and GA algorithms.

\begin{tabular}{lcc}
\hline Algorithms & Number of individuals & Max. iterations \\
\hline NSGA-III for top-level model & 40 & 500 \\
GA for bottom-level model & 40 & 500 \\
\hline
\end{tabular}

TABLE 5: The values of $f 1$ and $f 2$ in 20-turn random experiment.

\begin{tabular}{lcccc}
\hline Turn & $f 1$ & Sampling error of $f 1$ & $f 2$ & Time $($ sec.) \\
\hline 1 & 5264756 & -80683 & 4394 & 1320 \\
2 & 5438353 & 67043 & 4394 & 1428 \\
$\ldots$ & $\ldots$ & $\ldots$ & 4394 & 1365 \\
18 & 5268428 & -54543 & 4394 & 1518 \\
19 & 5238616 & 119054 & 4394 & 986 \\
20 & 5264756 & -50871 & & \\
\hline
\end{tabular}




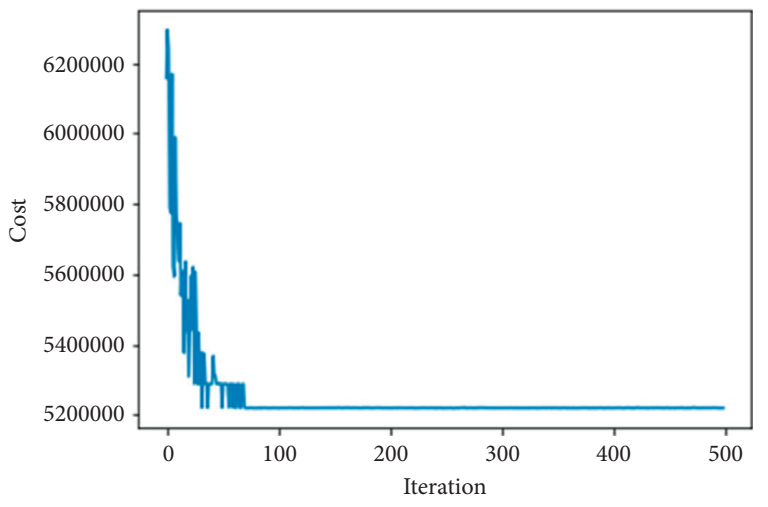

Figure 5: The value of objective function $f 1$ in all iterations.

TABLE 6: The business links between collection centers and recycling agencies/stations.

\begin{tabular}{lcc}
\hline Collection centers & Recycling stations & Group volume \\
\hline 2 & $0,5,6,7,13,32,33$ & 677 \\
7 & $2,4,8,10,14,18,31$ & 723 \\
8 & $19,22,28,29,34,37$ & 548 \\
10 & $1,9,12,17,23,30$ & 749 \\
14 & $11,16,21,24,25,27,38,39$ & 799 \\
16 & $3,15,20,26,35,36,40,41,42,43$ & 898 \\
\hline
\end{tabular}

$$
r c=\left\{\begin{array}{cccc}
1 & 0 & \cdots & 1 \\
0 & 0 & \cdots & 0 \\
\cdots & & & \\
0 & 1 & \cdots & 0
\end{array}\right\} .
$$

\section{Conclusions}

As was illustrated in the introduction and related study sections, at present, considering the regulations enforced by Chinese government and the structure of the reverse supply chain, the disposal factories can hardly establish their own recycling stations to directly collect WEEE from the customers. They had to cooperate with the third-party recycling agencies/stations to set up their own local collection centers to collect more WEEE with lower logistic cost. Moreover, the WEEE disposal volume must meet with the 20 percent of the licensed volume to get the subsidies from the government. Through the experiment in this paper, the bilevel programming-based location model was proved to work with considerably stable convergence and optimization performance. It met the requirements of disposal factories and the recycling agencies/stations and considered the regulations issued by the Chinese government. It can be a new useful approach to the treatment of WEEE in China.

However, the study introduced in this paper was based on the current situation of China WEEE policies which was still in practice now; therefore, the model should be improved according to the change of related policies. Meanwhile, even the model proposed in this paper was Chinese market-oriented, and if the business mode of other countries was similar to that of China, the model was also available through minor revision in variables and objective function definition, especially in developing countries. However, since the WEEE business was heavily affected by the regulations or policies, the proposed model was not completely guaranteed to universally work well.

In addition, more factors such as competition among WEEE disposal companies and the income from the disposal of WEEE were not considered. The cost and volume were not calculated elaborately with category of WEEE, either. As a result, the objective functions and constraints were not perfectly defined in the proposed model, which led to few nondominated solutions for business managers. In future study, these unconsidered factors should also be considered to improve the optimal model for better planning result.

\section{Data Availability}

The data used to support the findings of this study are available from the first author upon request.

\section{Conflicts of Interest}

The authors declare that there are no conflicts of interest.

\section{Acknowledgments}

The authors would like to thank Liaoning Normal University for the funding, lab facilities, and all the necessary technical support.

\section{References}

[1] Y. Luo, L. Cheng, L. Liao, and S. Wang, "Study on recover system of waste electronic and electrical equipment in China," 
Recyclable Resources and Circular Economy, vol. 2006, no. 1, pp. 31-34, 2006.

[2] J. Lu, Y. Pang, and X. Chang, "Comparative research on WEEE extended producer responsibility between America and Japan and its implication," Journal of East China Normal University(Humanities and Social Sciences), vol. 46, no. 2, pp. 131-137, 2014.

[3] L. Yang, M. Lu, and X. Zhang, "Current situation of regulations on recycling and disposal of waste electronic and electrical equipment," Journal of Jianghan University(Natural Science Edition), vol. 47, no. 2, pp. 124-131, 2019.

[4] B. H. Robinson, "E-waste: an assessment of global production and environmental impacts," Science of the Total Environment, vol. 408, no. 2, pp. 183-191, 2009.

[5] S. N. M. Menikpura, A. Santo, and Y. Hotta, "Assessing the climate co-benefits from waste electrical and electronic equipment (WEEE) recycling in Japan," Journal of Cleaner Production, vol. 74, no. 1, pp. 183-190, 2014.

[6] H. Xu and W. Zhou, "Japan's WEEE management and its enlightenment to China," Environmental Protection, vol. 47, no. 18 , pp. 59-62, 2019.

[7] G. T. Temur and B. Bolat, "Evaluating efforts to build sustainable WEEE reverse logistics network design: comparison of regulatory and non-regulatory approaches," International Journal of Sustainable Engineering, vol. 10, no. 6, pp. 358-383, 2017.

[8] CCID Group, The Report of Chinese Electronic and Electrical Equipment (EEE) Market in 2019, CCID Group, Shanghai, China, 2020, http://www.cena.com.cn/special/2020jdscbg.

[9] J. Kou, "How to regulate the recycling of WEEE," 2020, http:// pic.people.com.cn/n1/2020/0115/c1016-31549476.html.

[10] Intelligence Research Group, The Investigation and Investment Research of China WEEE Industries from 2020 to 2026, Intelligence Research Group, Thrissur, India, 2019, https:// www.chyxx.com/research/201911/801384.html.

[11] The State Council of People's Republic of China, Measures for the Collection and Use of Waste Electrical and Electronic Equipment Processing Fund, The State Council of People's Republic of China, Beijing, China, 2012, http://www.gov.cn/ gzdt/2012-05/30/content_2149195.htm.

[12] Ministry of Commerce of People's Republic of China, China's Renewable Resources Recycling Industry Development Report, Beijing, China, 2018, http://ltfzs.mofcom.gov.cn/article/date/ 201806/20180602757116.shtml.

[13] P. Golinska and A. Kawa, Dynamic Recovery Network for WEEE. EcoProduction: Environmental Issues In Logistics And Manufacturing, pp. 75-89, Springer, Berlin Germany, 2012.

[14] S. Shokohyar and S. Mansour, "Simulation-based optimisation of a sustainable recovery network for Waste from Electrical and Electronic Equipment (WEEE)," International Journal of Computer Integrated Manufacturing, vol. 26, no. 6, pp. 487-503, 2013.

[15] G. Ravi, S. Pandian, and W. Abdul-Kader, "Performance evaluation of reverse logistics enterprise-an agent-based simulation approach," International Journal of Sustainable Engineering, vol. 10, no. 6, pp. 384-398, 2017.

[16] C. L. Popa and C. E. Cotet, "Virtual model in monitoring and optimization of a selective waste collection integrated system," in Proceedings of the 5th International Conference on Advanced Manufacturing Engineering and Technologies, V. Majstorovic and Z. Akovljevic, Eds., pp. 41-55, Lecture Notes in Mechanical Engineering, Springer, Cham, Switzerland, 2017.
[17] A. A. Llamas, N. J. Bartie, M. Heibeck, M. Stelter, and M. A. Reuter, "Simulation-based exergy analysis of large circular economy systems: zinc production coupled to CdTe photovoltaic module life cycle," Journal of Sustainable Metallurgy, vol. 6, no. 6, pp. 34-67, 2020.

[18] A. Ç. Suyabatmaz, F. T. Altekin, and G. Şahin, "Hybrid simulation-analytical modeling approaches for the reverse logistics network design of a third-party logistics provider," Computers \& Industrial Engineering, vol. 70, no. 70, pp. 74-89, 2014.

[19] J. Mar-Ortiz, B. Adenso-Diaz, and J. L. González-Velarde, "Design of a recovery network for WEEE collection: the case of Galicia, Spain," Journal of the Operational Research Society, vol. 62, no. 8, pp. 1471-1484, 2011.

[20] I. Tari and S. A. Alumur, "Collection center location with equity considerations in reverse logistics networks," INFOR: Information Systems and Operational Research, vol. 52, no. 4, pp. 157-173, 2014.

[21] J. Baxter and E. Bø, "The effects of geographical, operational and service parameters on WEEE transport networks," International Journal of Logistics Research and Applications, vol. 20, no. 4, pp. 342-358, 2017.

[22] W. Di, G. Chen, and Y. Yue, "A collection station location choice for waste household electrical appliance return based on bi -level programming," Industrial Safety and Environmental Protection, vol. 39, no. 9, pp. 72-74, 2013.

[23] M. Huang and J. Zhang, "Simulation of waste mobile phone recycling point location planning," Computer Simulation, vol. 35, no. 7, pp. 394-398, 2018.

[24] H. Yu and W. D. Solvang, "A general reverse logistics network design model for product reuse and recycling with environmental considerations," The International Journal of Advanced Manufacturing Technology, vol. 87, pp. 2693-2711, 2016.

[25] N. Srinivas and K. Deb, "Muiltiobjective optimization using nondominated sorting in genetic algorithms," Evolutionary Computation, vol. 2, no. 3, pp. 221-248, 1994.

[26] K. Deb and H. Jain, "An Evolutionary many-objective optimization algorithm using reference-point-based nondominated sorting approach, part i: solving problems with box constraints," IEEE Transactions on Evolutionary Computation, vol. 18, no. 4, pp. 577-601, 2014.

[27] J. Jazzbin, "Geatpy: the genetic and evolutionary algorithm toolbox with high performance in python," 2020, http:// geatpy.com.

[28] W. Di and J. Wang, "Study on multi-objective satisfaction optimization of location problem of waste household appliance reclamation stations," Logistics Technology, vol. 31, no. 21, pp. 269-272, 2012. 